\title{
Larvicidal action of Nux-vomica (Strychnus nux-vomica L.) against Diamond back moth (Plutella xylostella L.)
}

\author{
C. Selvaraj ${ }^{*}$, J. S. Kennedy and M. Suganthy \\ INDIA \\ *Corresponding author. E-mail: selvaarjun665@gmail.com \\ Received: October 28, 2016; Revised received: June 6, 2017; Accepted: October 22, 2017
}

Department of Agricultural Entomology, Tamil Nadu Agricultural University, Coimbatore-641003 (Tamil Nadu),

\begin{abstract}
The present investigation reports on larvicidal efficacy of plant extracts of Nux-vomica, Strychnus nuxvomica against Diamond back moth (DBM). In this investigation shade dried and powdered nux-vomica plant samples (leaves, root bark, stem bark, seed and fruit rind) were extracted with organic solvents ethanol, methanol, acetone, hexane and chloroform and also formulated as Emulsifiable Concentrates (EC) using surfactant and solvents. This formulated plant extracts were tested against third instar larvae of DBM for larvicidal efficacy using leaf disc bioassay method under laboratory condition. Among the five solvent extracts tested, hexane extracts of root bark 11.11 EC @ 2 \% showed highest larval mortality of $76.66 \%$ followed by seed 14.25 EC, leaf 16.66 EC, stem bark 12.50 EC and fruit rind 12.50 EC extracts exhibited maximum mortality @ 2 \% concentration recording 66.66, 63.33, 56.66 and 40.00 per cent mortality respectively. Positive and negative control such as respective solvent and water showed 10.00 and $3.33 \%$ larval mortality respectively. The results of these experiment clearly indicate that nuxvomica plant possess promising larvicidal action against diamond back moth
\end{abstract}

Keywords: Alkaloids, larvicidal action, Nux-vomica, Solvent extracts, Plutella xylostella

\section{INTRODUCTION}

Caulifloweris important cruciferous vegetable grown in India with an area of $4,33,870$ hectares (Annonymous, 2016). Diamond back moth (DBM) is notorious pest of cauliflower (NIPHM, 2014).An estimate of the total cost associated with damage and management of DBM world wide was 4-5 billion USD per annum (Zalucki et al., 2012).In India Krishnamoorthy (2004) reported 52\% yieldloss in crucifers due to Diamond Back Moth. Management of this pest has become a remarkable task and farmers apply chemical pesticides once in a week for the effective management of this pest. However indiscriminate use of chemicals has resulted in problems like resurgence, resistance, replacement, impact on non-target organisms, including humans, environmental pollution. Sole reliance on insecticides has facilitated rapid build-up of resistance in the multivoltine DBM, which undergoes 20 generations a year in the tropics (Talekar and Shelton, 1993). To overcome resistance in DBM to insecticides, farmers often increase the doses of insecticides when insecticides alone account for between 30 and 50 per cent of the total cost of production and health problems with farmers were also common in states where these crops are grown (Weinberger and Srinivasan, 2009).

Increasing awareness about the deleterious effects of insecticides. Now farmers and researchers are switching over to botanical pesticides, which overcome many problems associated with chemical insecticides especially in the vegetables. In nature more than 1800 plant species are reported to have biopesticidal properties (Grainge et al., 1984). Our present studies in Nuxvomica (Strychnus nux-vomica) belongs to the family Loganiaceae commonly known as poison nut, snake wood, strychnine tree, quaker buttons andyetti. It has alkaloids such as strychnine, brucine, vomicine etc. The alkaloids content also varies according to plant parts. Seeds of nux-vomica contain 0.4 and $0.6 \%$ strychnine and brucine, respectively. Other parts of the tree have varying percentage of these two alkaloids viz., 1.7 and $2.8 \%$ in root bark, 0.3 and $0.4 \%$ in rootwood, 0.9 and $2.1 \%$ in stem bark, 0.5 and $0.01 \%$ in stem wood and 0.2 and $0.5 \%$ in leaves, respectively (Bisset et al. 1976) By keeping above aspects in mind, experiments were conducted to test the larvicidal efficacy of organic solvent extracts of different plant samples of nux-vomica against Diamond back moth Plutella xylostella L..

\section{MATERIALS AND METHODS}

Collection and processing of plant samples: Details on availability of Strychnus nux-vomica L. were collected from Botanical Survey of India (BSI), Coimbatore in Tamil Nadu. Different plant parts viz., leaves, seeds, stem bark, root bark and fruit rind of S. nux-vomica were collected from drought prone area of Krishnagiri district of Tamil Nadu. Fresh leaves, stem bark, root bark, fruits 
and seeds each weighing almost $3 \mathrm{~kg}$ were collected from the trees and brought to the laboratory (Plate 1). The plant samples were shade dried in the Entomology laboratory, TNAU, Coimbatore up to two weeks and grind into fine powder and packed in $3 \mathrm{~kg}$ plastic containers separately for further usage.

Extraction of active principles from plant samples: Dry powders of plant samples were packed in filter paper made $20 \mathrm{~cm} \times 4.5 \mathrm{~cm}$ size cylindrical thimbles. The samples filled thimbles were kept in the cylindrical sample holder present in the soxhelt apparatus and filled with organic solvents such as ethanol, methanol, acetone, hexane and chloroform individually. Plant samples were extracted with organic solvents. When organic solvents mixed with plant samples it produced coloured solution, extraction was done upto this coloured solution became transparent. During extraction process temperature maintenance was an essential task. Over temperature leads to explosion. Temperature ranges vary according to the solvents used for extraction process, temperature maintained during extraction process were viz., ethanol $\left(79^{\circ} \mathrm{C}\right)$, methanol $\left(65^{\circ} \mathrm{C}\right)$, acetone $\left(56^{\circ} \mathrm{C}\right)$, hexane $\left(69^{\circ} \mathrm{C}\right)$, chloroform $\left(61^{\circ} \mathrm{C}\right)$. This extraction process has taken approximately $12-18 \mathrm{~h}$ for each samples. The extracts were collected in $50 \mathrm{ml}$ screw capped vials and excess solvents evaporated in hot water bath $\left(65^{\circ} \mathrm{C}\right)$ and concentrated extracts stored at $4^{\circ} \mathrm{C}$ for further usage by following Yadav et al. (2014) with slight modification.

Preparation of EC formulation: Two fifty milliliter capacity beaker was kept in electronic balance, tarred the weight of plastic container and $1 \mathrm{~g}$ of crude extract was transferred to plastic containers from screw cap vials. Suggested EC formulation solvent cyclohexanone added drop by drop to the crude extract using micropipette, till crude extract completely soluble in the solvent. Then $1 \mathrm{ml}$ of surfactant such as tween 20 or triton $\mathrm{X}$ added to the solution. EC formulation must be stable upto $15 \mathrm{~min}$ and give milky appearance when dissolved in water. This test was carried out by transferring $1 \mathrm{ml}$ of EC solution to $50 \mathrm{ml}$ test tube filled with water. Observation was done after $15 \mathrm{~min}$ for whether particles float or settle downside rather it completely miscible. If sometimes particles does not miscible, instead floated on surfaces, in this cases experiment was carried out again. Finally EC formulations were brought to insectary, dissolved to needed concentration with water and progressed the bioassay.

Mass culturing of diamond back moth in laboratory: The culture was started from field collected larvae and maintained on cauliflower leaves, in the laboratory at $27 \pm 2{ }^{0} \mathrm{C}$. The plastic cups were kept inversely, on those cups fresh cauliflower leaves were placed. Entire larval period, larvae were fed with enough amount of cauliflower leaves by frequently changing the leaves day by day. When the larvae pupate in the leaf, the pupae was collected using brush in a petriplate and
Treatments details: EC formulations of extracts of S. nux-vomica used in larvicidal bioassay were following below:

\begin{tabular}{lc}
\hline Name of the extracts & EC formulation \\
\hline Ethanol extracts of nux-vomica leaf & $22.22 \mathrm{EC}$ \\
Ethanol extracts of nux-vomica root bark & $12.50 \mathrm{EC}$ \\
Ethanol extracts of nux-vomicastem bark & $12.50 \mathrm{EC}$ \\
Ethanol extracts of nux-vomica seed & $12.50 \mathrm{EC}$ \\
Ethanol extracts of nux-vomica fruit rind & $10.00 \mathrm{EC}$ \\
Solvent ethanol alone ( positive control) & - \\
Water alone (Negative control) & - \\
\hline
\end{tabular}

placed in moth emergence cage, into which the cabbage leaves or mustard seedlings grown in disposable cups and 10 per cent honey solution was provided. The emerging adults were started to laying eggs in large numbers in the mustard seedlings or cabbage leaves. Fresh mustard seedlings/leaves were provided for egg laying. The neonate larvae was transferred into the cabbage leaves by gentle tapping and also by placing the cabbage leaves nearer to the mustard seedlings (with touching) upon which the eggs were laid. The larvae were provided with fresh leaves daily and pupae were collected and placed in moth emergence cage to continue the cycle.

Larvicidal bioassay: Leaf-dip bioassay as per Tabashnik et al. (1991) was employed for larvicidal bioassay. Cauliflower leaves were first washed with distilled water and air-dried. Leaf disc of $9 \mathrm{~cm}$ diameter were cut and dipped in different concentrations viz., 0.5, 1, 1.5 and $2 \%$ of extracts of S. nux-vomica EC formulations. Each disc was dipped for 10-20 seconds and allowed to air-dry for a period of one hour. After complete evaporation, the leaves were transferred to clean bioassay containers over a moistened filter paper. The leaf discs were placed slantingly to rest on side of the container so that larvae can move on either side. Ten $3^{\text {rd }}$ instar larvae $(\sim 0.8 \mathrm{mg})$ of diamond back moth $(P$. xylostella) were released in each disc and three replicates were maintained per treatment. A treatment water alone served on to negative control and pure solvents at different concentration act as a positive control. Larval mortality was recorded every $24 \mathrm{~h}$, consecutively for 3 days. All the experiments were carried out in a room temperature with a photoperiod of 12:12 (L:D) and experiments with control mortality more than $20 \%$ were discarded and repeated.

In the same way larvicidal bioassay were conducted in addition to ethanol, solvents extracts of methanol, acetone, hexane and chloroform also conducted. Per cent larval mortality was calculated by following (Arivoli and Tennyson, 2013).

$$
\text { Per cent larval mortality }=\frac{\text { Number of dead larvae }}{\text { Total number of treated larvae }} \times 100
$$

In larvicidal bioassay experiments few larvae were died naturally. This natural mortality were corrected using standard formula given by (Abbots, 1925). 


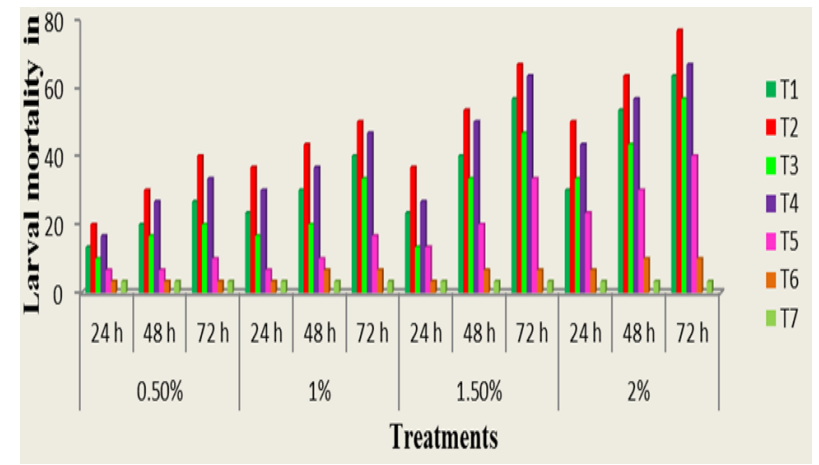

$\mathrm{T}_{1}$ - Hexane extracts of $S$. nux-vomica leaf, $\mathrm{T}_{2}$ - Hexane extracts of $S$. nux-vomica root bark, $\mathrm{T}_{3}$ - Hexane extracts of $S$. nux-vomica stem bark, $\mathrm{T}_{4}$ - Hexane extracts of $S$. nux-vomica seed , $\mathrm{T}_{5^{-}}$Hexane extracts of $S$. nux-vomica fruit rind, $\mathrm{T}_{6^{-}}$ Hexane alone, $\mathrm{T}_{7}$ - Water alone

Fig. 1. Larvicidal effect of hexane extracts of Strychnus nuxvomica Linn.

$$
\text { Corrected mortality }=\frac{(\mathrm{P}-\mathrm{P} 0)}{(100-\mathrm{P} 0)} \times 100
$$

Where,

$\mathrm{P}_{0}$ - Larvae mortality in control

$\mathrm{P}$ - Larvae mortality in treatment

Statistical analysis: The data obtained from laboratory experiments were analyzed in completely randomized design (CRD) (Gomez and Gomez, 1984). The mean values were separated using Least square Difference (LSD). The median lethal dose $\left(\mathrm{LD}_{50}\right)$ and Median lethal concentration $\left(\mathrm{LC}_{50}\right)$ of insecticides used were determined by Finney's probit analysis (Finney, 1971). The corrected per cent mortality was worked out using the formula given by Abbots, 1925.

Corrected per cent mortality $=\mathrm{P}_{\mathrm{t}}-\mathrm{P}_{\mathrm{c}} / 100-\mathrm{P}_{\mathrm{c}} \times 100$

Where,

$\mathrm{P}_{\mathrm{t}}$ - Observed mortality in treatment

$\mathrm{P}_{\mathrm{c}}$ - Observed mortality in untreated check

\section{RESULTS AND DISCUSSION}

The data summarized on table 1,3,5,7 and 9 represents the larval mortality of DBM varied from plant samples to plant samples and solvents to solvents. Maximum larval mortality was recorded in hexane extracts of nux -vomica root bark 11.11 EC @ 2\% concentration which is $76.66 \%$ followed by seed $14.25 \mathrm{EC}$, leaf 16.66 EC, stem bark 12.50 EC and fruit rind 12.50 EC extracts recorded maximum mortality@2\% concentration which is $66.66,63.33,56.66$ and 40.00 per cent respectively. In all plant samples order of efficacy was more or less same (Tables 1,3,5,7 and 9) (fig. 1).

Among five plant samples tested for bioefficacy study, hexane extracts of nux-vomica root bark samples was found to be more effective with $\mathrm{LC}_{50}$ value of $0.85 \%$ which is followed by seed $(1.07 \%)$, leaf $(1.34 \%)$, stem (1.75\%)and fruit rind (2.78\%)@2\% concentration of formulations (Tables 2,4,6,8 and 10).This larval

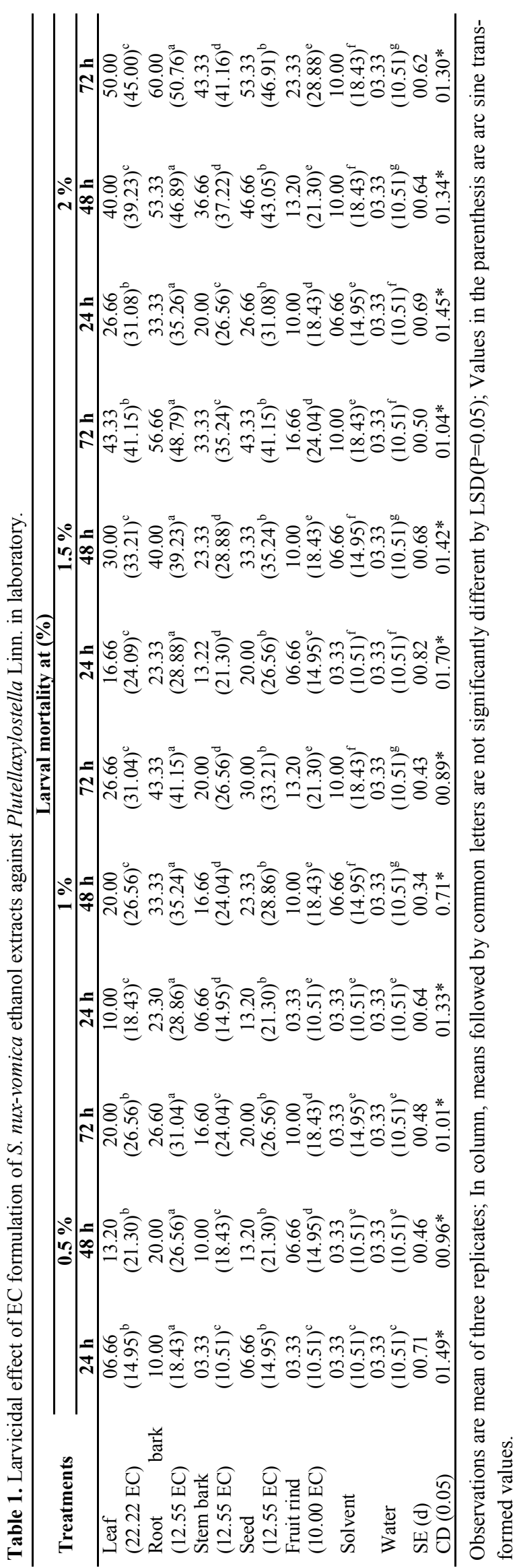



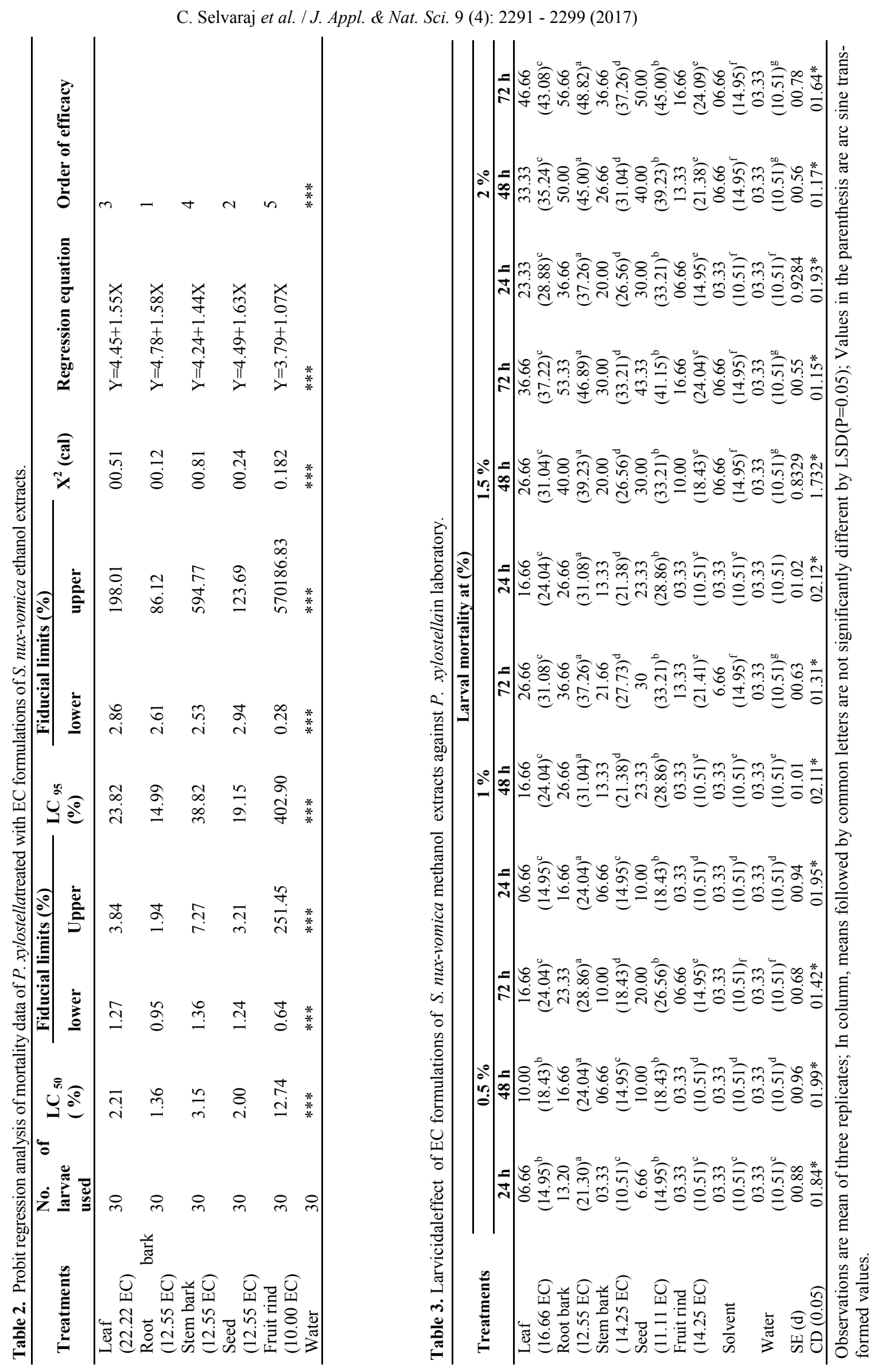
C. Selvaraj et al. / J. Appl. \& Nat. Sci. 9 (4): 2291 - 2299 (2017)
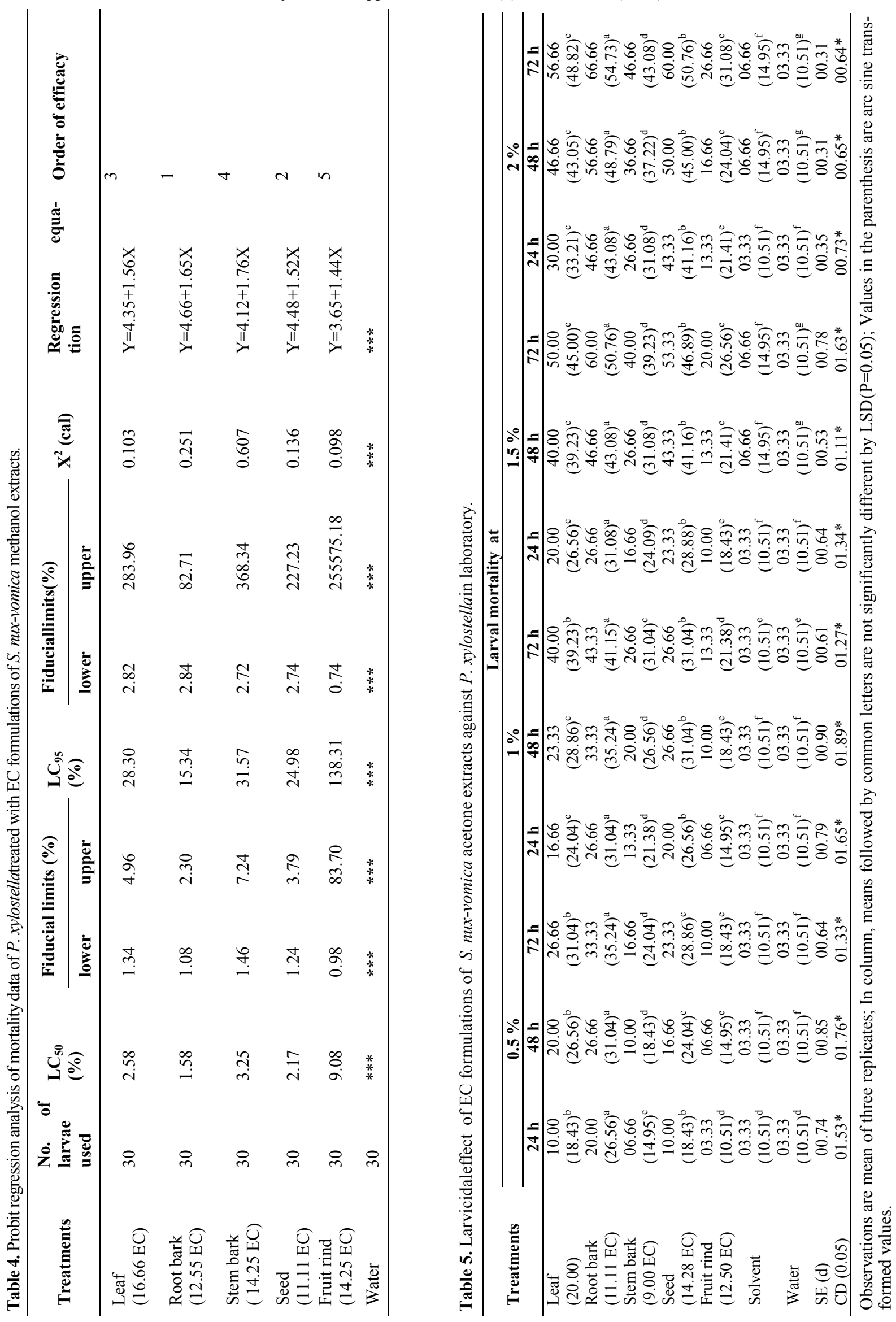
C. Selvaraj et al. / J. Appl. \& Nat. Sci. 9 (4): 2291 - 2299 (2017)
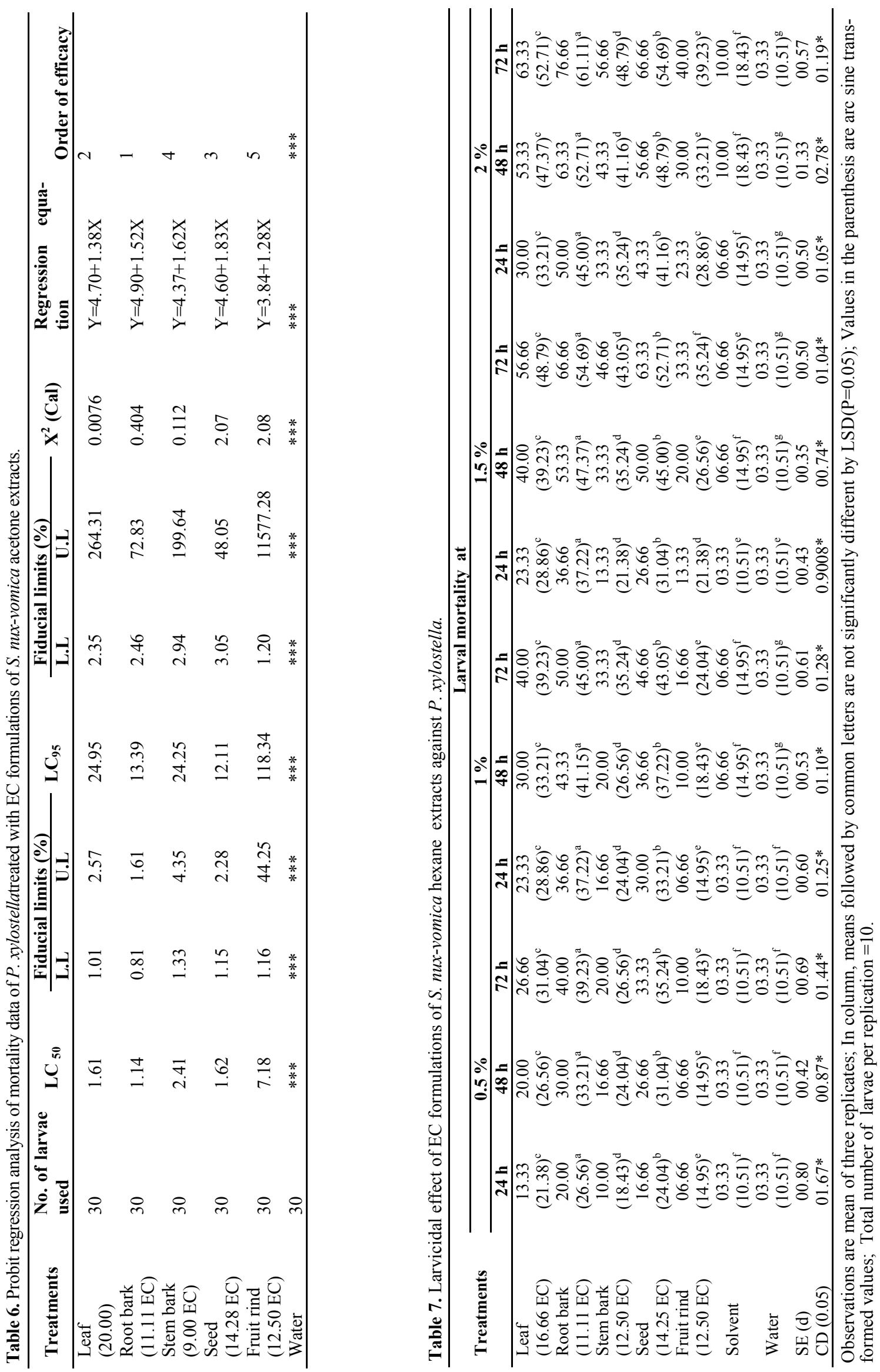
C. Selvaraj et al. / J. Appl. \& Nat. Sci. 9 (4): 2291 - 2299 (2017)
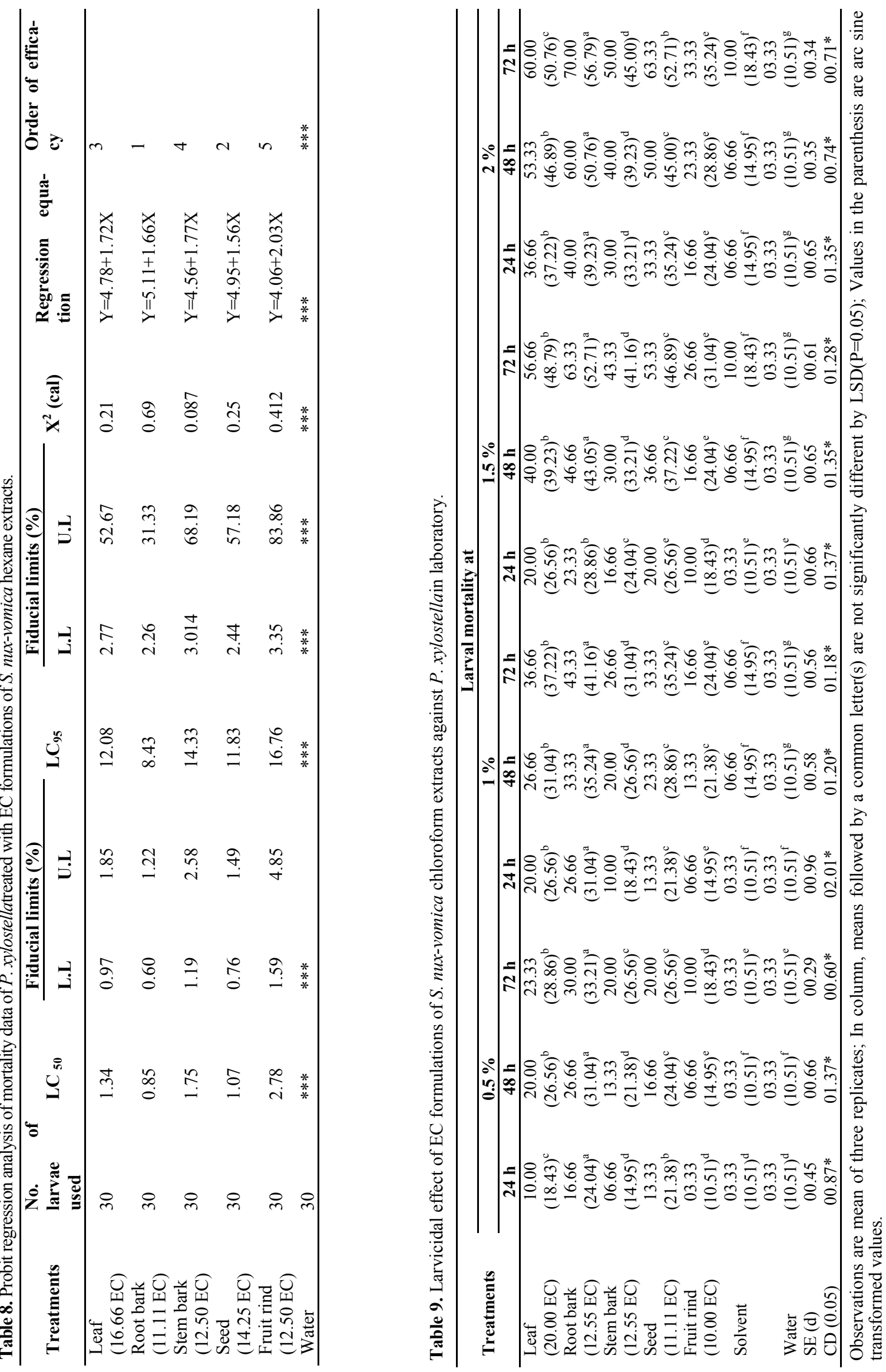


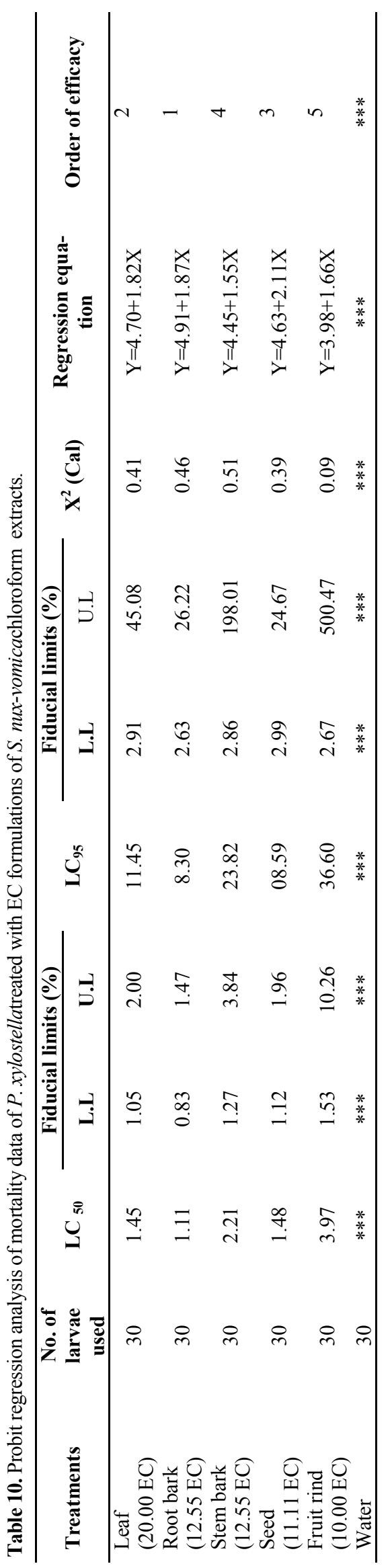

mortality variations are due alkaloids content variation from plant samples to plant samples and types of solvent used for extraction purposes. Literature on bio efficacy of nux-vomica against DBM is scanty or nil. So I am comparing my studies with available literature on botanicals against DBM. Morallo-Rejesus (1982) reported that ethanol extracts of Piper nigrum L. Against $P$. Xylostella Linn. revealed a $\mathrm{LC}_{50}$ value 1.819 per cent. Sood and Sharma (2010) found that ethanol extracts of Adiantumcapillus-Veneris against P. xylostella L. recorded maximum mortality 75 per cent at $20,000 \mathrm{ppm}$ in $72 \mathrm{HAT}$ and $\mathrm{LC}_{50}$ value of $6777.66 \mathrm{ppm}$.

The extracts of Vitexnegundo, Clerodendrum inerme, Lantana camera, and Eupatorium odoratum caused highest mortality against $A$. janata, $P$. xylostella and $S$. litura larvae in the laboratory assay (Kulkarni, 2002; Yankanchi, 2003). Methanol extracts of Adiantumcapillus-Veneris showed 70 per cent mortality at 20,000ppm in 72 HAT and $\mathrm{LC}_{50}$ value was 7,683.89 ppm (Sood and Sharma, 2010). Methanol extracts of $S$. nux-vomica showed 86.00 per cent mortality at 1,000 ppm concentration against Teak defoliator, $H y$ bleapurea C. (Senthil kumar et al., 2012). According to Senthil kumar et al. (2012) acetone extracts of $S$. nux-vomica L. showed 86.67 per cent larval mortality to teak defoliator, H. pureaC.at 1000 ppm concentration.

Hexane extracts of $S$. nux-vomica L. exhibited 100 per cent larval mortality against $C$. quinquefasciatus Say. 48 HAT at 1000 ppm concentration and recording LC $_{50}$ Value 261.91 ppm (Arivoli and Tennyson, 2012). Chloroform extracts of $S$. nux-vomica exhibited 100 per cent larval mortality against $C$. quinquefaciatus Say. at $1000 \mathrm{ppm}$ in 48 HAT treatments and the $\mathrm{LC}_{50}$ values was 1291.2 (Arivoli and Tennyson,2012). Obviously literatures of Arivoli and Tennyson. (2012) on larvicidal efficacy of $S$. nux-vomica against $C$. quinquefaciatus Say and Senthilkumaret al. (2012) on insecticidal properties of $S$. nux-vomica against Teak defoliator, $H$. pureasupports to my research work.

\section{Conclusion}

Totally five plant samples of nux-vomica with five different solvents combination were tested. Among them nux-vomica root samples extracted with hexane showed highest mortality of $76.66 \%$ against third instar larvae of Diamond back moth at root bark 11.11 EC formulation@2\% concentration. This result indicates the larvicidal action of nux-vomica against diamond back moth. Though root samples had maximum mortality, collecting root samples is tedious process. Instead of that we can utilize seeds for industrial purposes which also showed $66.66 \%$ mortality against third instar larvae of the moth. 


\section{ACKNOWLEDGEMENTS}

The corresponding author is thankful to Dr.J.S. Kennedy (Professor), Dr.M. Suganthi (Assit. Professor) and Dr.S.JeyarajanNelson (Professor), Department of Agricultural Entomology, TNAU, Coimbatore-641003 (Tamil Nadu), India for their support and suggestions.

\section{REFERENCES}

Abbots, W.S.(1925). A method for computing the effectiveness of an insecticide. J. Econ. Entomol., 18: 265-267.

Annonymous, (2016). www. Indiastat.com

Arivoli, S. and Samuel Tennyson. (2012). Larvicidal Efficacy of Strychnos nux vomica Linn. (Loganiaceae) Leaf Extracts Against the Filarial Vector CulexquinquefasciatusSay (Diptera: Culicidae). World J. Zool., 7: 06-11.

Bisset, N.G. and Phillipson, J.D. (1976). The Asian species of Strychnos. Part IV. The alkaloids.Lloydia.39. 263-325.

Finney, D. J. (1971). Probit Analysis, Cambridge University Press, London, UK.

Gomez, K. A. and Gomez, A. A. (1984).Statistical procedures for agricultural research. John Wiley and Sons. New York.650 .

Grainge, M., S., Ahmed, W. C., Mitchell. and J. W. Hylin. (1984). Plant species reportedly possessing pest-control properties-A database. Resource Systems Institute, East -West Center, Honolulu, Hawaii, U.S.A. 240 pp.

Krishnamoorthy, A.(2004). Biological control of diamondback moth.Plutella xylostella (L). an Indian scenario with reference to past and future strategies. In Kirk, A.A.Bordat, D.(Eds.), Proceedings of the International symposium, 21-24 October 2002, Montpellier, France, CIRAD, pp. 204-211.

Kulkarni, R.D.(2002). Formulation of botanical insecticides.Ph. D. Thesis, Karnataka University, Dharwad, PP. 83-92

Morallo-Rejesus, B.(1982). Botanical Insecticides Against the Diamondback Moth. Department of Entomology,
College of Agriculture, University of the Philippines at LosBanos, College, Laguna, Philippines.

NIPHM (2014). National Institute of Plant Health management, Hyderabad. Integrated pest Management (IPM) practices packages.

Senthilkumar, S., Murugesan, K., Vijayalakshmi, B., Monisha, M. Suresh Babu, D., Lakshmidevi, R. and Manivachakam, P. (2012). Insecticidal Properties of Certain Flora based on Ethnobotanical Records Against Teak defoliator, H. puera Cramer (Lepidoptera: Hybaeidae). Europ. J Exp. Biol., 2: 513-519.

Sood, S. and Sharma, N.(2010). Insect Growth Regulatory Activity of Adiantum Capillus Veneris Against Plutella xylostella and Aphis Craccivora in Ethanol and Methanol.Res. J. Agric. and Biol. Sci., 6: 785-790.

Tabashnik, B. E., Finson, N. and Johnson, M.W.(1991). Managing resistance to Bacillus thuringiensis: Lessons from the diamondback moth (Lepidoptera: Plutellidae). J. Econ. Entomol.,84: 49-55.

Talekar, N.S. and A.M. Shelton. A.M.(1993). Biology, ecology and management of diamondback moth. Annu. Rev. Entomol., 38: 275-301.

Weinberger, K. and Srinivasan, R.(2009). Farmer's management of cabbage and cauliflower pests in India and their approaches to crop protection. J. Asia Pacific Entomol., 12: $253-259$.

Yadav, M., Chatterji, S., Gupta, S.K. and Watal, G. (2014). Preliminary phytochemical screening of six medicinal plants used in traditional medicine.International journal of pharmacy and pharmaceutical sciences.6:539-542.

Yankanchi, S. R.(2003). Studies on the insecticidal properties of certain plant extracts. Ph. D. Thesis, Karnataka University, Dharwad, 56-68 PP.

Zalucki, M.P., Shabbir, A., Adamson, D., Shu-Sheng, L. (2012). Estimating the economic cost of one of the world's major insect pests, Plutella xylostella L. (Lepidoptera; Plutellidae): just how long is a piece of string.J. Econ. Entomol., 105: 1115-1129. 